\section{References}

1. Parikh $S A$, Rabe KG, Call TG, Zent CS, Habermann TM, Ding $W$, Leis JF, Schwager SM, Hanson CA, Macon WR, Kay NE, Slager SL, Shanafelt TD. Diffuse large B-cell lymphoma (Richter syndrome) in patients with chronic lymphocytic leukaemia (CLL): a cohort study of newly diagnosed patients. Br J Haematol 2013;162:774-782.

2. Kroft SH, Dawson DB, McKenna RW. Large cell lymphoma transformation of chronic lymphocytic leukemia/small lymphocytic lymphoma. A flow cytometric analysis of seven cases. Am J Clin Pathol 2001;115:385-395.

3. Parikh SA, Kay NE, Shanafelt TD. How we treat Richter syndrome. Blood 2014:123:1647-1657.
4. Tsimberidou AM, O'Brien S, Khouri I, Giles FJ, Kantarjian HM, Champlin R, Wen S, Do KA, Smith SC, Lerner S, Freireich EJ, Keating MJ. Clinical outcomes and prognostic factors in patients with Richter's syndrome treated with chemotherapy or chemoimmunotherapy with or without stem-cell transplantation. J Clin Oncol 2006;24:2343-2351.

5. Verma V, Giri S, Bhatt VR, Amador-Ortiz A, Armitage JO. Synchronous or metachronous hairy cell leukemia and chronic lymphocytic leukemia: a case series and literature review. Front Oncol 6:270.

6. Wei Q, Sebastian S, Papavassiliou P, Rehder C, Wang E. Metachronous/ concomitant B-cell neoplasms with discordant light-chain or heavy-chain isotype restrictions: evidence of distinct B-cell neoplasms rather than clonal evolutions. Hum Pathol 2014;45:2063-2076.

\title{
Non-Leukemic Granulocytic Sarcoma Presenting with Multiple Lymphadenopathies
}

\section{Çoklu Lenfadenopati ile Ortaya Çıkan Alösemik Granülositik Sarkom}

\author{
Ayfer Gedük', Esra T. Demirsoy ${ }^{1}$, Süheyla U. Bozkurt² ${ }^{2}$ Zafer Gülbaş ${ }^{3}$, Serkan İşgören ${ }^{4}$ \\ ${ }^{1}$ Kocaeli University Faculty of Medicine, Department of Hematology, Kocaeli, Turkey \\ ${ }^{2}$ Marmara University Faculty of Medicine, Training and Research Hospital, Department of Pathology, Istanbul, Turkey \\ ${ }^{3}$ Anadolu Medical Center, Bone Marrow Transplantation Center, Kocaeli, Turkey \\ ${ }^{4}$ Kocaeli University Faculty of Medicine, Department of Nuclear Medicine, Kocaeli, Turkey
}

\section{To the Editor,}

Granulocytic sarcoma (GS) is a rare tumor with poor prognosis that is composed of primitive myeloid cells, localized in extramedullary sites. The incidence is $2.5 \%-9.1 \%$ in acute myeloid leukemia (AML) patients and it may also occur in association with a myeloproliferative neoplasm or myelodysplastic disorders. The most common locations are the skin, lymph nodes, gastrointestinal tract, bones, and soft tissues [1].

A 68-year-old man presented with the complaint of bilateral inguinal swelling. On physical examination bilateral cervical, axillary, and inguinal multiple lymphadenopathies (LAP), approximately 2-3 cm in diameter, were noted. Initial workup revealed normal liver and renal functions; negative viral serology for epstein-barr virus, cytomegalovirus, HIV, and hepatitis $B / C$;

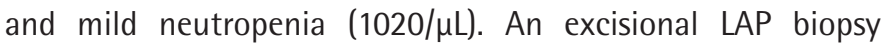
revealed disruption of the normal lymph nodal architecture by a diffuse monomorphic infiltrate comprising medium-sized mononuclear cells with a high nuclear cytoplasmic ratio and fine chromatin pattern. In immunohistochemical study, these cells were positive for $\mathrm{CD} 34, \mathrm{CD} 43, \mathrm{CD} 117$, and myeloperoxidase and negative for Tdt, CD3, CD5, CD20, CD15, CD30, CD56, EMA and Pax-5. The Ki-67 proliferation index was $45 \%$ and EBER was negative. Leukemic infiltration could not be detected in the bone marrow examination. Cytogenetic analysis was negative for $t(9,22), t(15,17), t(8,21)$, and inv16 but positive for NPM1 and $11 \mathrm{q} 23$ rearrangement. The results confirmed the diagnosis of GS (Figures 1A-1C). A positron emission tomography/ computed tomography (PET/CT) scan showed multiple hypermetabolic lymph nodes $\left(\mathrm{SUV}_{\max }: 11.8\right)$ in bilateral cervical, axillary, paracardiac, and both common iliac areas (Figure 1D). Cytosine-arabinoside plus idarubicin ( $3+7$ regimen) was started. PET/CT was repeated after chemotherapy and revealed partial response (Figure 1E). The persistent disease was confirmed by an excisional LAP biopsy and a fludarabine, cytarabine, G-CSF and idarubicin regimen was started. Since complete metabolic response was detected in the follow-up PET/CT, he underwent a matched related donor reduced-intensity conditioning hematopoietic stem cell transplantation (HSCT) (Figure 1F). He engrafted successfully and has had no recurrent GS for 8 months since the transplant.

Although it is well recognized that GS can cause localized lymphadenopathy, manifestation as bilateral multiple LAP is 


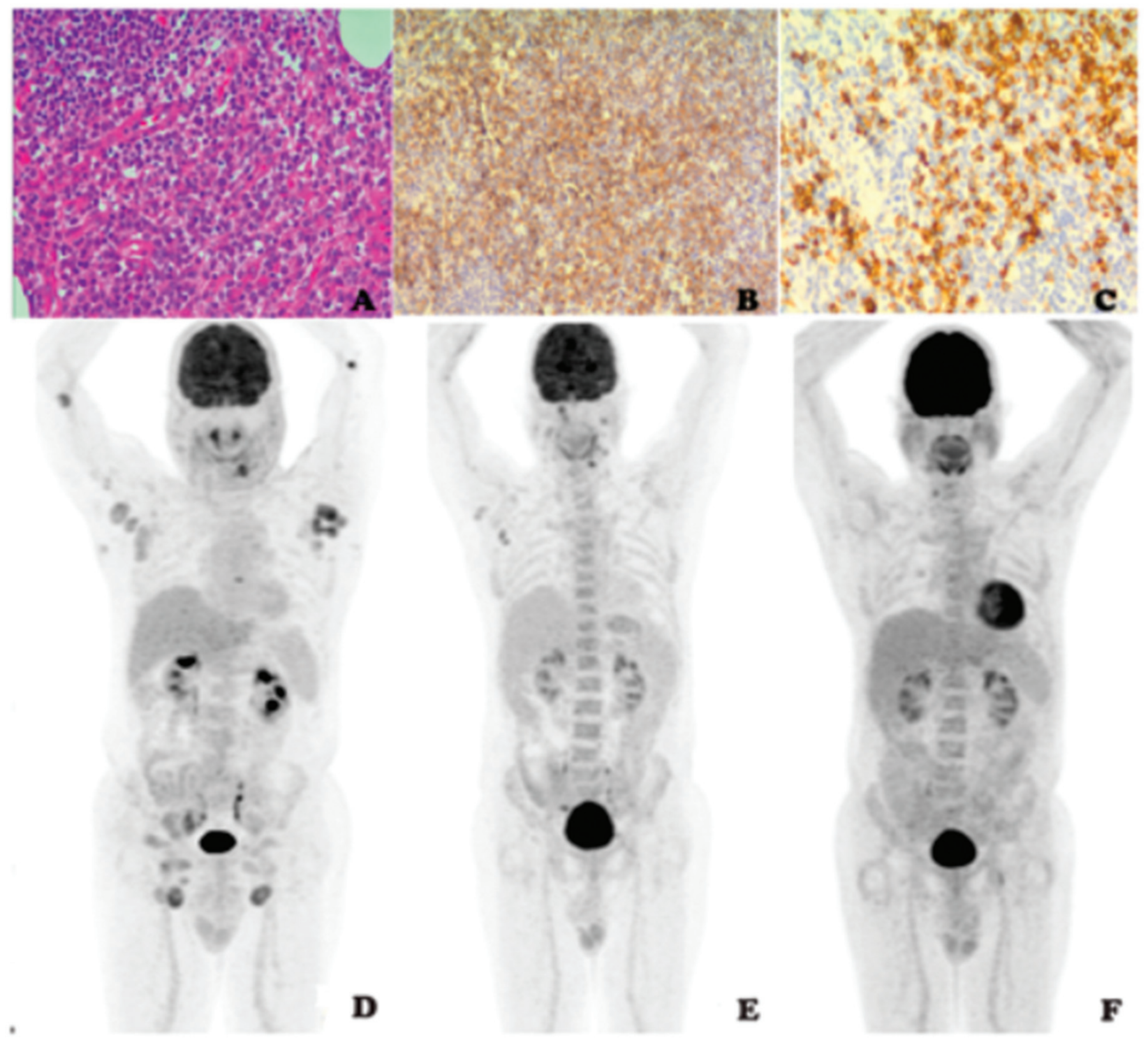

Figure 1. A) Large neoplastic cells infiltrating paracortical areas of the lymph node (hematoxylin and eosin, 400). B) Immunohistochemistry showing CD34 immunoreactivity in the cytoplasm of the neoplastic cells (CD34 stain, 400). C) Immunohistochemistry showing myeloperoxidase immunoreactivity in the cytoplasm of the neoplastic cells (myeloperoxidase stain, 400). D) Initial positron emission tomography/computed tomography (PET/CT) presents multiple hypermetabolic lymph nodes. E) PET/CT after 3+7 regimen shows partial response. F) PET/CT after fludarabine, cytarabine, G-CSF, and idarubicin regimen shows complete metabolic response.

rare [2]. Nandedkar et al. [3] reported a case of GS presenting with bilateral multiple LAP without evidence of leukemia, which is similar to our patient. In these two cases the interesting point is a myeloid malignancy presenting with only lymphatic spread. There is no consensus on the treatment of non-leukemic GS. Common practice suggests AML-like induction chemotherapies as first-line treatment and allogeneic HSCT for relapsed/ refractory disease. Radiotherapy and surgery are also options in selected cases [4]. In a study by Chevallier et al. [5] that assessed the outcome of 30 patients with non-leukemic GS who underwent allogeneic HSCT, 5-year overall survival and leukemia-free survival were $48 \%$ and $36 \%$, respectively. In another study, a significantly longer event-free survival rate was detected in patients treated with chemotherapy and allogeneic HSCT [6]. These data suggest that allogeneic HSCT is efficient as a consolidation regimen for GS. In our case, PET/CT was used for disease detection and in the monitoring of treatment response, which is an effective imaging tool for GS [7]. In conclusion, we present a case of GS with lymphatic spread like a lymphoma.

Keywords: Granulocytic sarcoma, Leukemia, Lymphadenopathy

Anahtar Sözcükler: Granülositik sarkom, Lösemi, Lenfadenopati 
Conflict of Interest: The authors of this paper have no conflicts of interest, including specific financial interests, relationships, and/or affiliations relevant to the subject matter or materials included.

\section{References}

1. Pileri SA, Ascani S, Cox MC, Campidelli C, Bacci F, Piccioli M, Piccaluga PP, Agostinelli C, Asioli S, Novero D, Bisceglia M, Ponzoni M, Gentile A, Rinaldi P, Franco V, Vincelli D, Pileri A Jr, Gasbarra R, Falini B, Zinzani PL, Baccarani M. Myeloid sarcoma: clinico-pathologic, phenotypic and cytogenetic analysis of 92 adult patients. Leukemia 2007;21:340-350.

2. Neiman RS, Barcos M, Berard C, Bonner H, Mann R, Rydell RE, Bennett JM. Granulocytic sarcoma: a clinicopathologic study of 61 biopsied cases. Cancer 1981;48:1426-1437.
3. Nandedkar S, Kawatra M, Malukani K. Myeloid sarcoma de novo presenting as generalized lymphadenopathy. Clin Cancer Investig J 2013;2:86.

4. Yilmaz AF, Saydam G, Sahin F, Baran Y. Granulocytic sarcoma: a systematic review. Am J Blood Res 2013;3:265-270.

5. Chevallier P, Labopin M, Cornelissen J, Socié G, Rocha V, Mohty M; ALWP of EBMT. Allogeneic hematopoietic stem cell transplantation for isolated and leukemic myeloid sarcoma in adults: a report from the Acute Leukemia Working Party of the European Group for Blood and Marrow Transplantation. Haematologica 2011;96:1391-1394.

6. Antic D, Elezovic I, Milic N, Suvajdzic N, Vidovic A, Perunicic M, Djunic I, Mitrovic M, Tomin D. Is there a "gold" standard treatment for patients with isolated myeloid sarcoma? Biomed Pharmacother 2013;67:72-77.

7. Lee EYP, Anthony MP, Leung AYH, Loong F, Khong PL. Utility of FDG PET/CT in the assessment of myeloid sarcoma. AJR Am J Roentgenol 2012;198:11751179.

\title{
A Case of Leukemia Cutis with Acute Myeloid Leukemia on Azacitidine Therapy
}

\author{
Akut Miyeloid Lösemide Azasitidin Tedavisi Altında Lösemi Kutis Olgusu
}

\author{
Asude Kara ${ }^{1}$, Aslı Akın Belli ${ }^{1}$, Volkan Karakuş², Yelda Dere ${ }^{3}$, Erdal Kurtoğlu \\ ${ }^{1}$ Department of Dermatology, Muğla Sıtkı Koçman University Training and Research Hospital, Muğla, Turkey \\ ${ }^{2}$ Department of Hematology, Muğla Sıtkı Koçman University Training and Research Hospital, Muğla, Turkey \\ ${ }^{3}$ Department of Pathology, Muğla Sıtkı Koçman University Faculty of Medicine, Mugla, Turkey \\ ${ }^{4}$ Department of Hematology, Antalya Training and Research Hospital, Antalya, Turkey
}

\section{To the Editor,}

Leukemia cutis (LC) is an extramedullary form of leukemia. The frequency and onset age of $\mathrm{LC}$ depends on the subtype of underlying leukemia. Clinical presentations of $\mathrm{LC}$ can be variable but it generally appears as nodules and plaques [1]. Herein, we report a case of LC with acute myeloid leukemia on azacitidine therapy.

A 70-year-old male presented with spontaneous ecchymoses and weakness in the Hematology Outpatient Clinic. Physical examination was normal. Laboratory tests were as follows: hemoglobin: $4.1 \mathrm{~g} / \mathrm{dL}$, leukocyte count: $17.600 / \mathrm{mm}^{3}$, platelet count: $57.000 / \mathrm{mm}^{3}$, and lactate dehydrogenase: $605 \mathrm{U} / \mathrm{L}$. Peripheral blood smear revealed $60 \%$ myeloblasts. Eighty percent of blastic infiltration and positive staining with myeloperoxidase (MP0) were detected in the bone marrow biopsy. The patient was diagnosed with acute myelomonocytic leukemia (AML-M4) with the morphological and immunopathological findings. Flow cytometry of the bone marrow or peripheral blood was not done. In the conventional cytogenetic analysis done before the treatment, 20 metaphases were detected. Six of them had "add" (46,XY,add(8)(q24)[6]) and 10 were diploids and 4 were hypodiploids. In the fluorescence in situ hybridization (FISH) analysis [5q31, t(15;17)(q22-24;q21), trisomy $8, \mathrm{t}(9 ; 22)$ (q34; $q 11.2), \operatorname{inv}(16)(p 13 q 22)$, del7q31, del/inv11q23, monosomy $7, t(8 ; 21)(q 21.3 ; q 22)$, and del20q], there was no abnormality.

After four cycles of therapy with azacitidine $\left(75 \mathrm{mg} / \mathrm{m}^{2}\right.$ daily for 7 days in a month), the need for red blood cells decreased but the need for platelets remained. Furthermore, some skin lesions appeared on the trunk. On dermatological examination, multiple discrete, violaceous-erythematous papules and nodules were observed on the trunk (Figures 1a and 1b). Histopathological examination of the skin lesions showed blastic cell infiltration with large pleomorphic nuclei and narrow cytoplasm in the dermis and also positive staining with CD34, CD117, and MPO (Figures 1c and 1d). The patient was diagnosed with LC with AML-M4 relapsed in the bone marrow synchronously and the 